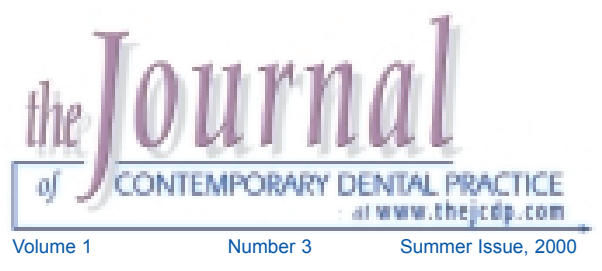

\title{
Coaching for a Winning Dental Team
}

\section{Steven Schwartz, DDS}

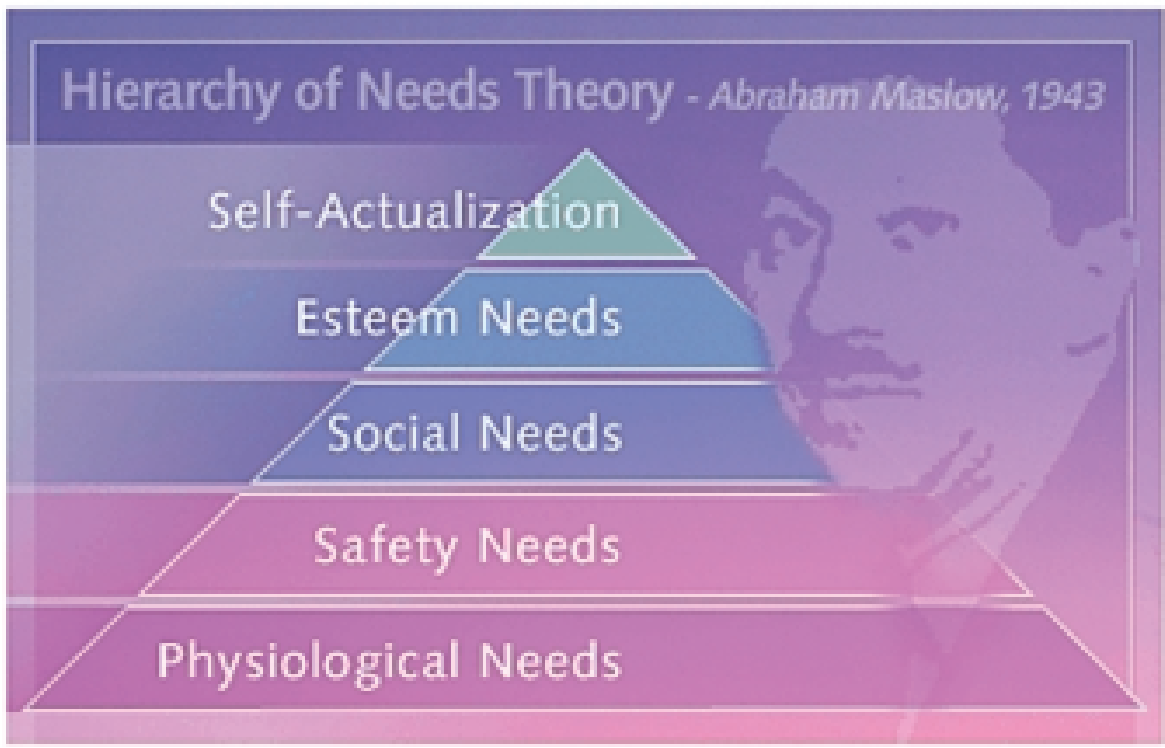

\begin{abstract}
In 1943, Abraham Maslow, the "father of humanistic psychology," formulated his "Hierarchy of Needs Theory." Maslow proposed people have needs that must be satisfied, and these needs will motivate until they are satisfied. The needs are arranged in a hierarchy or pyramid ranging from basic needs to higher needs with an individual needing to satisfy a lower need before a higher need can motivate. The five needs of the hierarchy are: physiological needs, safety needs, social needs, esteem needs, and self-actualization. This article discusses adaptation of the hierarchy of needs to the dental practice to motivate staff to perform at a higher level.
\end{abstract}

Keywords: Abraham Maslow, staff motivation, dental practice management 


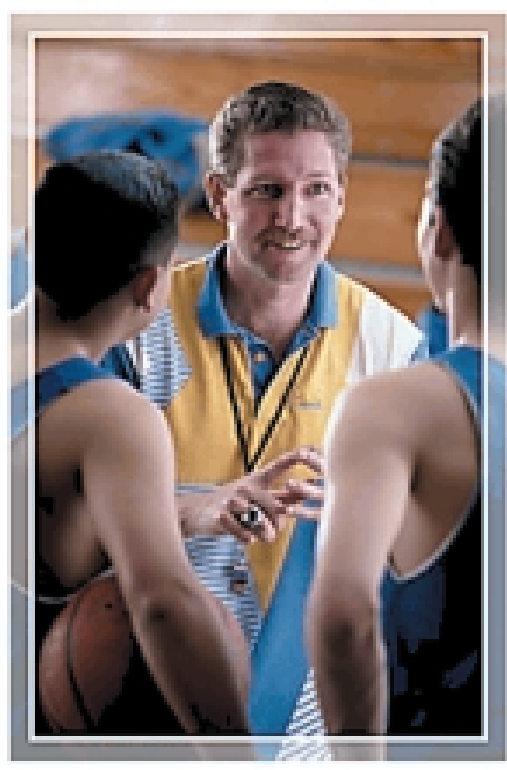

\section{Introduction}

Years ago most employers motivated employees by behaving like law-enforcement officers. Workplace rules and production standards were established solely by the boss. If employees failed to follow these rules or failed to meet production levels, they were punished through pay reductions or job termination. Over the years, motivational theories have changed so the employer has assumed the role of a coach rather than a cop. A coach of a sports team provides the player with the equipment, training, and strategies to win games. Similarly, an employer provides the employees with the equipment, training, and motivation necessary to provide exceptional service and products to customers.

During the 1940's, Abraham Maslow1 established the groundwork for current employee motivational techniques. Maslow is now considered the father of humanistic psychology. Humanistic psychology incorporates aspects of both behavioral psychology and psychoanalytic psychology. Behavioral psychologists follow the teachings of Skinner who believed that human behavior is controlled by external environmental factors. On the other hand, psychoanalytic psychologists follow the teachings of Freud who proposed the idea human behavior is controlled by internal unconscious forces. Maslow's motivation theory states that human behavior is controlled by both external and internal factors and by the need for healthy humans to be the best they can be.

In 1943 Maslow formulated his "hierarchy of needs theory." Maslow proposed people have needs that must be satisfied, and these needs will motivate until they are satisfied.. The needs are arranged in a hierarchy ranging from basic to higher needs, with an individual needing to satisfy a lower need before a higher need can motivate. The five needs of the hierarchy are:

1. Physiological (hunger, thirst, shelter, sex)

2. Safety (security, protection from physical and emotional harm)

3. Social (affection, belonging, acceptance, friendship)

4. Esteem (also called ego). The internal ones are self-respect, autonomy, and achievement; the external ones are status, recognition, and attention.

5. Self-actualization (being the best at doing things)

Once a need is satisfied, it no longer motivates. For example, a starving man will do whatever is necessary to obtain food, but once he is fed, the promise of food no longer motivates him. Maslow proposed the "hierarchy of needs theory" not only worked in a social situation but also could be applied to the workplace. By arranging these needs in a pyramid, they can be used to motivate staff.

\section{Physiological Needs}




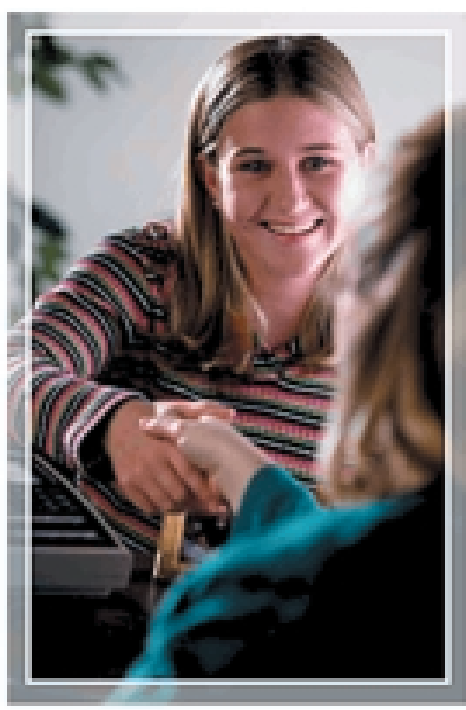

\section{Physiological Needs}

In a dental practice the dentist does not provide food and shelter to the staff but does provide the income to purchase them. Applying Maslow's theory, the most productive way to compensate staff is to provide a basic salary comparable to other practices, but add "partnership pay." In this model, the dentist pays the staff as if they were partners. Both the staff and dentist's compensation is based on how much net profit the practice generates. Periodically the staff is rewarded for their positive efforts on behalf of the practice by receiving a share of the practice profits (typically $20 \%$ ). Through profit sharing the staff can experience a tangible correlation between the quantity and quality of work they do and the money they earn. By seeing the "bottom line" each month they are more likely to be efficient, less wasteful, and more patient-centered.

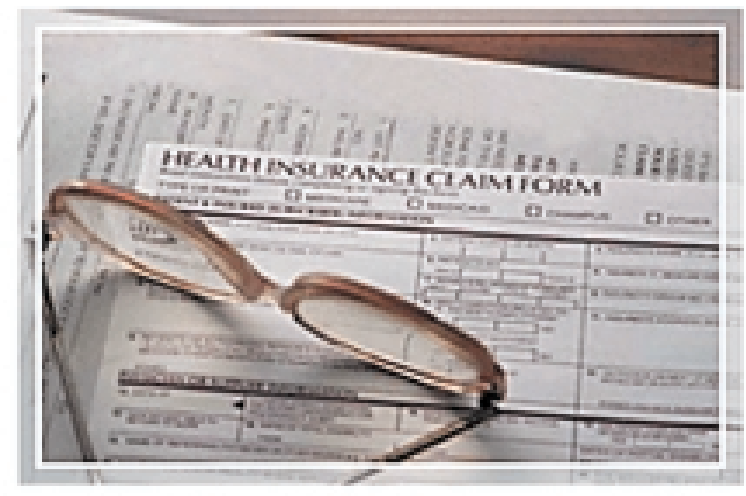

\section{Safety Needs}

Safety needs are not limited to satisfying OSHA guidelines. Under this need the employee is looking for health insurance, job security, and childcare. Many dentists feel that providing health insurance to the staff is an expense the practice cannot afford. However, if the dentist considers it can cost a practice in excess of $\$ 20,000$ to train a new employee, the annual premium for health insurance is well worth the benefit of retaining a motivated and productive team member. Furthermore, the dentist can control the cost of health insurance by setting minimum hours for staff to qualify for health benefits and requiring

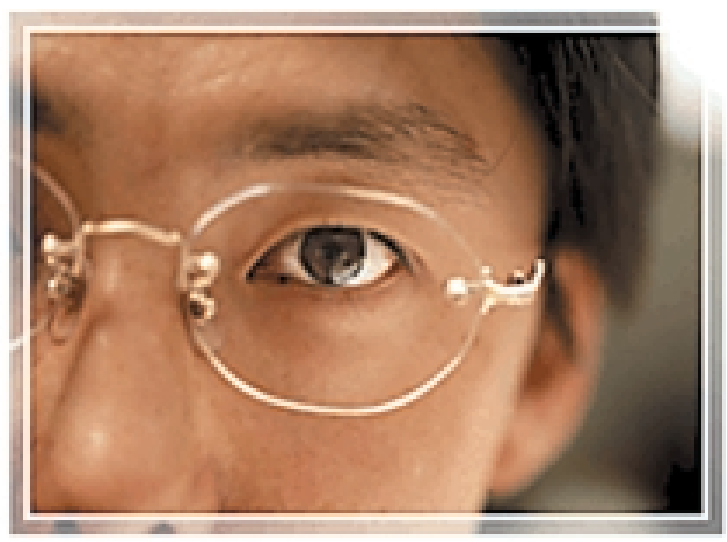

employees to share in the premium costs.

Staff allegiance to the practice increases in proportion to job security. The high production generated by Japanese workers can be partially attributed to the promise of a life long job by their employer. Successful American companies are taking the same initiative. When FedEx discontinued its company's Zapmail program in 1986, all 1300 of the employees who had worked in that department had first priority in acquiring other internal job opportunities. Those employees who could not find positions with equivalent salaries could accept lower level jobs and retain their previous salary for up to 15 months, or until they found another higher salary job. It is not surprising that FedEx is considered one of the top companies in customer service. 


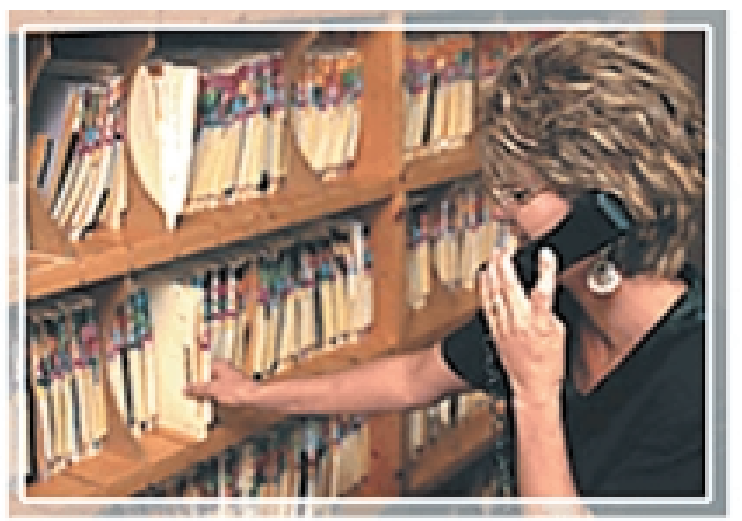

In the dental practice, staff should be crosstrained so they can be more productive by performing alternate tasks during slow periods. Should bad weather force patient cancellations, a dental assistant can be asked to review patient records and contact those who have not yet completed treatment or need to schedule a recall appointment rather than be sent home with loss of pay. Staff can also help market the practice during a lull in production. Providing health information at a shopping mall, a health fair, or in local schools can be an ethical and positive means of marketing for the dental practice.

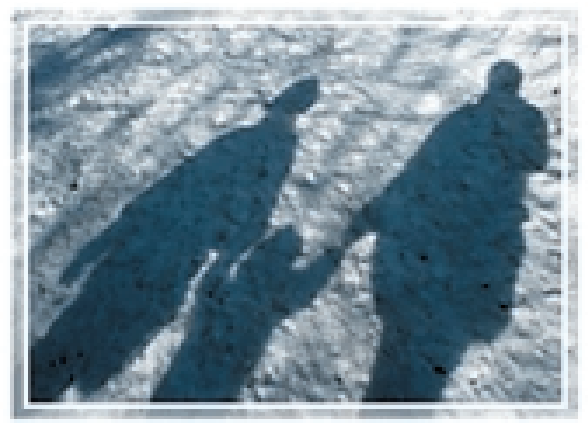

Childcare needs should also be addressed. Childcare does not have to be provided on a continual basis. However, facilities should be available when an employee is faced with a sick child, or an unexpected school closing. A spare room in the office can be set aside for children of staff members that need emergency daycare. If that is not possible, arrangements can be made with a local day care center for such emergency situations. The cost involved can be less than the expense of losing the services of a valuable employee for the day.

\section{Social Needs}

Humans have the need for friendship and acceptance. The theme song from the TV show "Cheers" poses the question, "Wouldn't you like to go where everybody knows your name?" If the dentist wants to create a warm feeling in the practice so patients feel welcome and accepted, then an atmosphere where the staff can experience those feelings must be established. This can be accomplished by promoting humor in the workplace. If the dentist doesn't promote laughter, the staff should be encouraged to intervene to create a light-hearted work environment for all to enjoy.

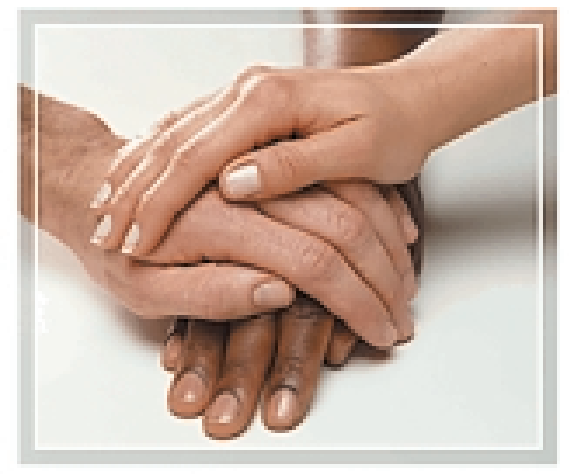

The dentist cannot be allowed to take him or herself too seriously. Patients tend to be happier and more relaxed in an office where there is happiness and humor. Camaraderie should be encouraged. Celebrate birthdays, practice anniversaries, promotions, etc. with barbecues, cakes, and ice cream for the entire dental team.

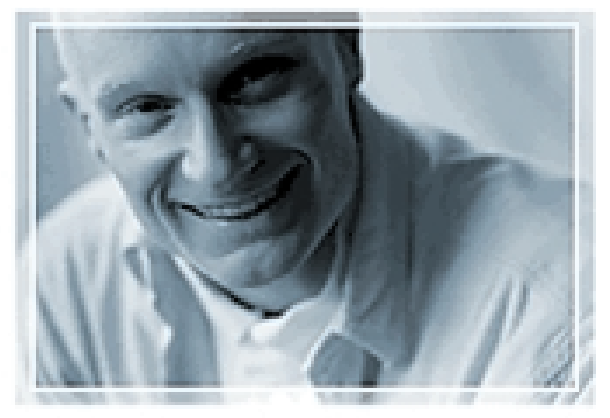




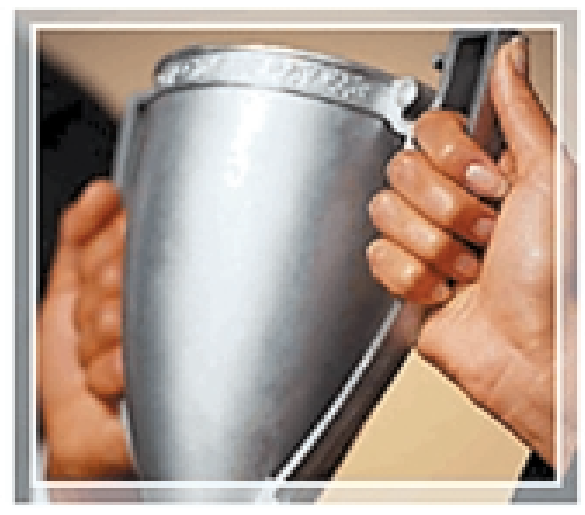

\section{Esteem Needs}

It is unfortunate if a staff member is only recognized or singled out when something goes wrong. The staff needs to sense appreciation and receive recognition for a job well done. In his book, 1001 Ways To Reward Employees, Robert Nelson2 states "While money is important to employees, what tends to motivate them to perform and to perform at higher levels, is the thoughtful, personal kind of recognition for a job well done."

Recognition can range from a simple thank you to more formal recognition. A public display of appreciation is one of the most effective means of motivation. The following are some suggestions for providing recognition:

\section{Some no-cost methods of recognition are:}

- Assign priority parking

- Wash the employee's car in the parking lot during lunch

- Name a space after the employee i.e., the Suzy Smith Hallway

\section{Low cost recognition can include:}

- A trophy cup filled with goodies

- Employee of the month T-shirts, pins, caps

\section{More formal recognition can include:}

- Tickets to shows, concerts

- Paid trips to seminars

- Gift certificates, membership at health clubs

\section{Self Actualization}

Self-actualization allows an employee to "Be all that you can be." The high school girl you hired as a file clerk does not want to remain in the chart room forever. She would like to advance to a position that provides for increased income, responsibility, and skills. Suggestions for inspiring staff to advance to a higher level include:

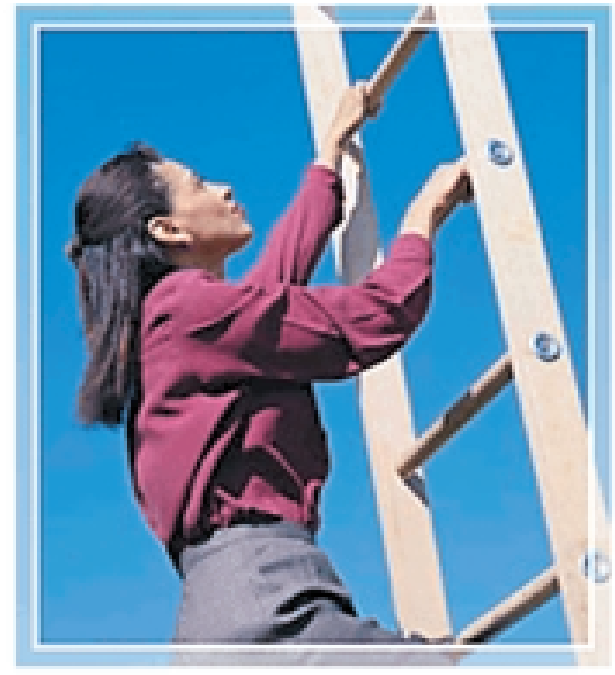

\section{Encourage advancement}

When filling an entry-level position, inform the new employee this is an entry-level position and hope that he/she advances to higher levels of responsibility and salary. Point out other staff members that have advanced since their hiring. Give the new staff member a goal to strive for.

\section{Promote from within}

When an advanced level position becomes available, avoid the urge to place an ad in the classified section. Look within the current staff for a replacement. Promoting existing staff has several advantages over hiring new staff. The personality, reliability, and honesty are known factors with an existing staff member. New employees often fail to live up to their resumes and letters of recommendations. Teaching new skills to an existing staff member that is familiar with office policies and traditions are simpler than teaching a new employee both new skills and office etiquette. Most important, by promoting a current staff member you motivate that person to perform at an even higher level. 


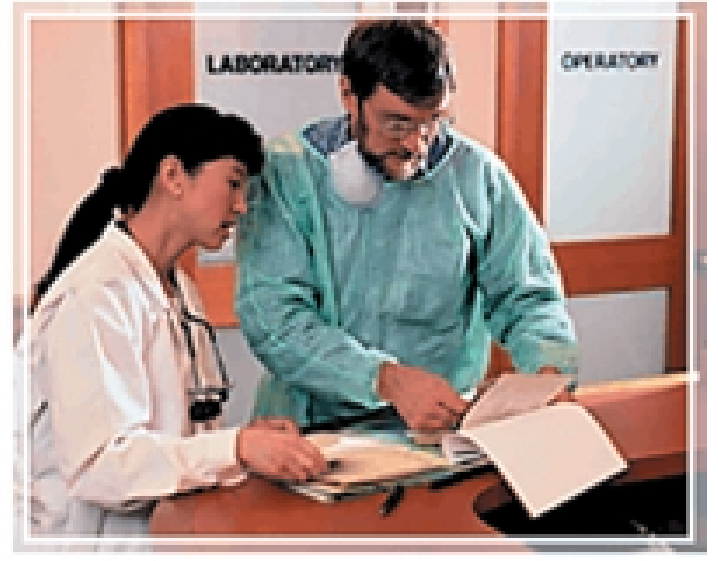

Delegate responsibility

Delegating responsibility to staff allows them to learn new skills and makes for a more interesting job. A side benefit is that it reduces stress on the dentist and upper level employees by allowing them to perform more productive duties.

\section{Continuous training - refining current and learning new skills}

Refining current skills and learning new ones, even without formal promotion, motivates an employee. It makes their job more interesting and more productive for the office. The better trained a staff member is, the easier it is to move that person into another position should the need arise.

\section{Summary}

One can compare the organization of a dental practice to a baseball team. The dentist is the coach. The coach cannot win games without motivated players eager to win. The players cannot win games without a coach to provide equipment, training, and motivation. The dental practice cannot grow and remain profitable unless the staff is provided with the equipment, training, and motivation to perform as a team dedicated to providing superior service to patients.

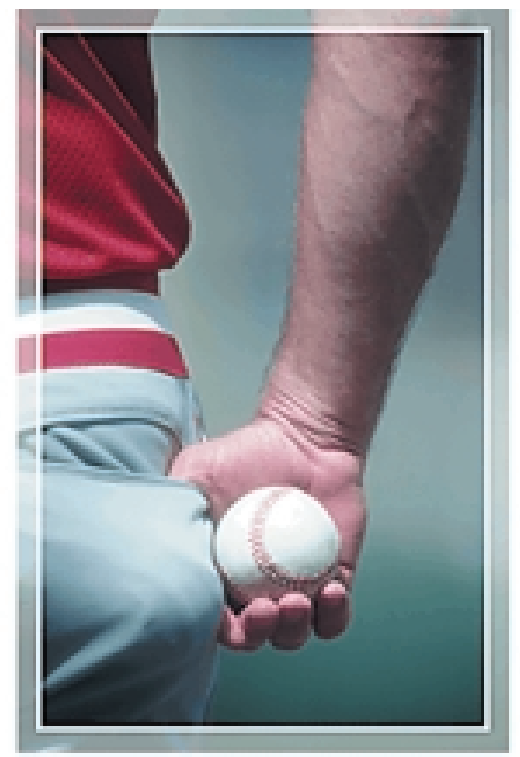

\section{References}

1. Maslow A, Stephens D, Heil G: Maslow on Management. New York, John Wiley and Sons, 1998.

2. Nelson, B: 1001 Ways to Reward Employees. New York, Workman Publishing, 1994

3. Rosenbluth, H: The Customer Comes Second. New York, William Morrow and Company, 1992.

\section{About the Author}

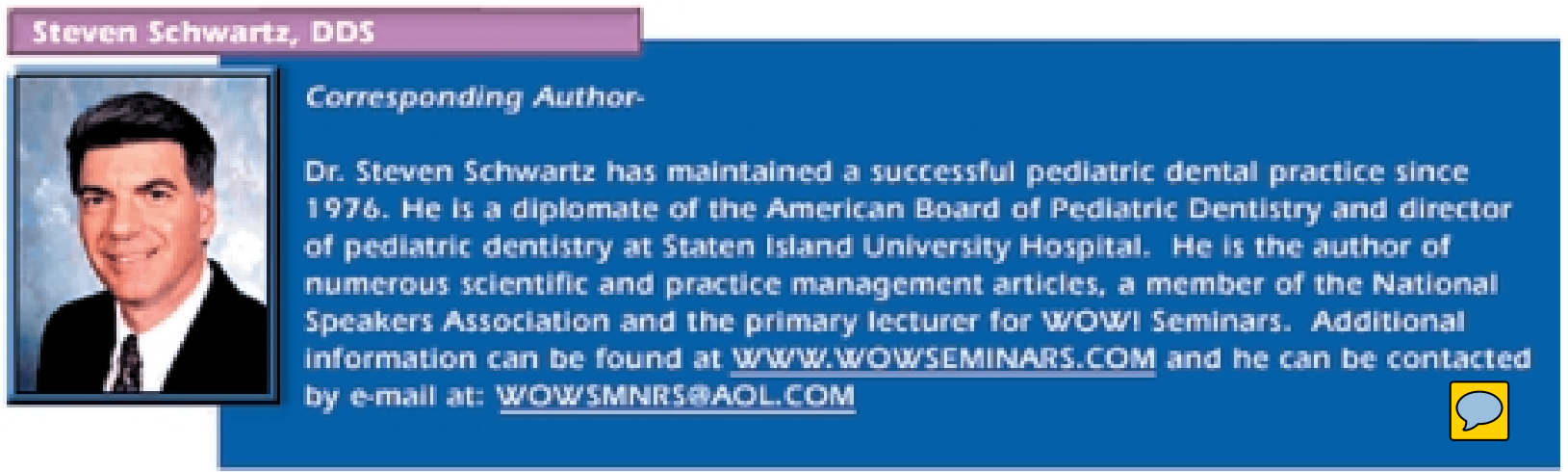

